\title{
A need for evidence-based clinical practice guidelines for the use of heparins in the elderly
}

This article was published in the following Dove Press journal:

Clinical Interventions in Aging

II April 2010

Number of times this article has been viewed

\author{
Isabelle Gouin-Thibault ${ }^{1,2}$ \\ Virginie Siguret ${ }^{1,2}$ \\ Eric Pautas ${ }^{2,3}$
}

'Assistance Publique Hôpitaux de Paris, Laboratoire d'Hématologie, Hôpital Charles Foix, Paris, France; ${ }^{2}$ Université Paris Descartes, INSERM U, Paris, France; ${ }^{3}$ Assistance Publique Hôpitaux de Paris, Unité de Gériatrie Aiguë, Hôpital Charles Foix, Paris, France

Correspondence: Isabelle Gouin-Thibault Laboratoire d'Hématologie, Hopital Charles Foix, 7 Avenue de la République, 94205 Ivry Sur Seine, France

$\mathrm{Tel}+33$ I 49594638

Fax +33 I 49594637

Email isabelle.gouin@cfx.aphp.fr

\begin{abstract}
Low-molecular-weight heparins (LMWHs) have been widely studied in pivotal clinical trials or in several meta-analyses. However, the safety and optimal use of LMWHs in high-risk patients such as the very elderly remains uncertain since these patients are usually excluded from clinical trials. In terms of LMWHs in the elderly, the main concerns are renal failure and the risk of accumulation. A clinical approach consisting of a LMWH dose reduction in the elderly should be considered with great caution in terms of efficacy, since it has been tested neither in the treatment of VTE nor in VTE prophylaxis. If monitoring is considered in patients receiving therapeutic dose LMWHs, appropriate target ranges for peak anti-Xa activity levels should be used and so far, no anti-Xa activity-based guidelines have been issued. Moreover, no data support any laboratory monitoring in elderly patients treated with prophylactic dose LMWHs.
\end{abstract}

Keywords: elderly patients, low-molecular-weight heparin, renal insufficiency, evidence-based medicine

The number of elderly patients who require anticoagulant therapy is rising steadily as the aging of the population is causing increases in the prevalence of venous and arterial thromboembolism. Due to the higher risk of bleeding, managing anticoagulants in these frail patients may be challenging. Among anticoagulants used to prevent or treat thromboembolism events, low-molecular weight heparins (LMWHs) have been widely studied in pivotal clinical trials or in several meta-analyses. However, despite their wide development and use, the safety and optimal use of LMWHs in high-risk patients such as the very elderly, remain uncertain since these patients are usually excluded from clinical trials. So far, only one study has been conducted in elderly patients with moderate to severe renal impairment: the "Innohep ${ }^{\circledR}$ in Renal Insufficiency Study" (IRIS). Unfortunately, this trial was prematurely stopped thus the results are unconclusive. ${ }^{1}$

In a recent issue of this Journal, Robert-Ebadi et al thoroughly reviewed the risk/benefit ratio of the use of anticoagulation in elderly patients and considered different approaches to improve safety in this population. ${ }^{2}$ One concern raised in this review is the increased risk of accumulation and bleeding in patients with impaired renal function receiving LMWHs, since LMWHs are mainly excreted by the kidney.

In patients with severe renal impairment (creatinine clearance $<30 \mathrm{~mL} / \mathrm{min}$ ) who require therapeutic anticoagulation, Robert-Ebadi et al suggest using unfractionated heparin instead of LMWHs. If LMWH is used in these patients, they suggest ' $L W M H$ with dose reduction ( $1 / 2$ dose).' These recommendations are in agreement with those 
of the Eighth American College of Chest Physicians (ACCP) Consensus Conference on Antithrombotic and Thrombolytic Therapy. ${ }^{3}$ It is noteworthy that the ACCP recommendations on this topic are weak with a low quality of evidence (grade 2C) and are mostly based on studies with enoxaparin. ${ }^{3}$ So far, the efficacy and safety of LMWHs used at reduced initial dosages have not been evaluated in the treatment of acute venous thromboembolism (VTE). ${ }^{4}$ A dose-adjustment proposal according to renal function has only been investigated in patients with acute coronary syndrome receiving enoxaparin: the authors of the study observed that a dose reduction leading to low anti-Xa levels $(<0.5 \mathrm{U} / \mathrm{mL})$ may increase the risk of mortality and recurrent ischemic events. ${ }^{5}$

A dose reduction is also suggested by Robert-Ebadi et al in patients receiving prophylactic doses of LMWHs in medical setting. The results of the two main clinical trials assessing the use of enoxaparin (MEDENOX) and dalteparin (PREVENT) for the prevention of venous thromboembolism in acutely ill medical patients do not support such an option. ${ }^{6,7}$ Indeed, in the MEDENOX study, the daily $40 \mathrm{mg}$ enoxaparin dosage was particularly effective in the group of patients older than 80 years (the risk reduction of VTE was $87 \%$ in patients 80 years and older as compared with $63 \%$ in the general study population), while the daily $20 \mathrm{mg}$ dosage was similar to placebo. ${ }^{6}$ Similarly, in the PREVENT study, the relative treatment effect of dalteparin was not attenuated when adjusted for age with a $48 \%$ reduction of VTE events in patients aged 75 years and older treated with dalteparin compared with patients receiving placebo, without an increase in major hemorrages. ${ }^{8}$ Thus, due to the lack of clinical evidence, we think that the decision to use reduced therapeutic or prophylactic dosages should be considered with great caution since it could be beneficial in terms of safety but deleterious in terms of efficacy.

To date it has not been demonstrated that plasma anti-Xa activity levels correlate with clinical outcomes. Dose finding studies with LMWHs used at curative doses have demonstrated that increasing the dose was associated with higher anti-Xa activity levels and an increased risk of major bleeding. ${ }^{10}$ Monitoring of anti-Xa activity in patient treated with therapeutic LMWH dose may be recommended to detect an overdosage and/or accumulation in patients with renal impairment. ${ }^{3}$ In their review, Robert-Ebadi et al suggest considering anti-Xa monitoring in elderly patients treated with therapeutic doses of LMWH and to use the target ranges of $0.6-1 \mathrm{IU} / \mathrm{mL}$ for twice-daily $\mathrm{LMWH}$ and 1-2 IU/mL for once-daily LMWHs. These ranges are those cited by Kearon et al in the Antithrombotic therapy for venous thromboembolism disease chapter of the ACCP guidelines. ${ }^{9}$ The use of these conservative target ranges may lead to a misinterpretation of the anti-Xa activity. Indeed, due to a better understanding of the pharmacodynamic profile of each LMWH preparation, more accurate target levels for anti-Xa activity have been published, especially by Hirsh et al in the Parenteral anticoagulants chapter of the same issue of the ACCP guidelines: $>1.0$ with enoxaparin; $0.87 \mathrm{IU} / \mathrm{mL}$ with tinzaparin; $1.34 \mathrm{IU} / \mathrm{mL}$ with once-daily and 1.01 with twice-daily nadroparin; $1.05 \mathrm{IU} / \mathrm{mL}$ with once daily and $0.59 \mathrm{IU} / \mathrm{mL}$ with twice-daily dalteparin. ${ }^{3,10}$ Moreover, it is noteworthy that so far, no dose adjustment guidelines based on anti-Xa activity are available.

Finally, in patients with severe renal impairment treated with prophylactic doses of LMWHs, Robert-Ebadi et al suggest to monitor anti-Xa activity to detect an accumulation based on Mahé et al study. ${ }^{11}$ However in the latter study, the authors came to the conclusion that 'the results do not support laboratory monitoring in patients treated with prophylactic doses of enoxaparin, even older patients with impaired renal function and/or low body-weight.' Indeed, they showed that in 125 acutely ill medical inpatients (mean age 87 years) receiving daily $4000 \mathrm{IU}$ of enoxaparin up to 10 days, the mean anti-Xa activity value was slightly but significantly higher during the course than at the beginning of therapy. The difference in mean anti-Xa activity levels between patients with versus those without severe renal impairment was only of $0.11 \mathrm{IU} / \mathrm{mL}$ and the mean peak anti-Xa value in patients with severe renal impairment was of $0.72 \mathrm{IU} / \mathrm{mL}$, ie, levels of anti-Xa activity not clearly associated with an increased risk of bleeding. ${ }^{11}$

In terms of LMWHs in the elderly, renal failure and the risk of accumulation is the main concern. However, other situations such as extreme body weight are also of concern. For thromboprophylaxis, a strong negative correlation was found between total body weight and anti-Xa levels in elderly inpatients treated with fixed-dose enoxaparin ${ }^{11}$ and in nonelderly obese patients treated with fixed-dose enoxaparin and nadroparin. ${ }^{3}$ Due to the paucity of data, no validated recommendations in these situations are available.

In conclusion, the approach consisting of a LMWH dose reduction in the elderly should be considered with great caution in terms of efficacy, since it has been tested neither in the treatment of VTE nor in VTE prophylaxis. If monitoring is considered in patients receiving therapeutic dose LMWHs, appropriate target ranges for peak anti-Xa levels should be used and so far, no anti-Xa based guidelines have been issued. Finally, no data support any laboratory monitoring in elderly patients treated with prophylactic doses LMWHs. Random- 
ized clinical trials specifically devoted to elderly patients are necessary to better evaluate the risk/benefit ratio of LMWHs in this population and to issue guidelines in this population.

\section{Disclosures}

The authors report no conflicts of interest in this work.

\section{References}

1. Leizorovicz A. Tinzaparin compared to unfractionated heparinfor initial treatment of deep vein thrombosis in very eldely patients with renal insufficiency-the IRIS trial. Blood. 2008;112:434 (ASH Annual Meeting Abstracts).

2. Robert-Ebadi H, Le Gal G, Righini M. Use of anticoagulants in elderly patients: practical recommendations. Clin Interv Aging. 2009;4:165-177.

3. Hirsh J, Bauer KA, Donati MB, Gould M, Samama MM, Weitz JI. Parenteral anticoagulants: American College of Chest Physicians evidence-based clinical practice guidelines (8th Edition). Chest. 2008;133:141S-159S.

4. Gouin-Thibault I, Pautas E, Siguret V. Safety profile of different low-molecular weight heparins used at therapeutic dose. Drug Saf. 2005;28(4):333-349.

5. Montalescot G, Collet JP, Tanguy ML, Ankri A, Payot L, Dumaine R, et al. Anti-Xa activity relates to survival and efficacy in unselected acute coronary syndrome patients treated with enoxaparin. Circulation. 2004;27;110(4):392-398.
6. Samama MM, Cohen AT, Darmon JY, Desjardins L, Eldor A, Janbon C, et al. Comparison of enoxaparin with placebo for the prevention of venous thromboembolism in acutely ill medical patients. Prophylaxis in medical patients with enoxaparin study group. $N$ Engl J Med. 1999;341:793-800.

7. Leizorovicz A, Cohen AT, Turpie AG, Leizorovicz A, Cohen AT, Turpie AG, et al. PREVENT medical thromboprophylaxis study group: randomized, placebo-controlled trial of dalteparin for the prevention of venous thormboembolism in acutely ill medical patients. Circulation. 2004;110:874-879.

8. Kucher N, Leizorovicz A, Vaitkus PT, Cohen AT, Turpie AG, Olsson CG, et al. PREVENT medical thromboprophylaxis study group. Efficacy and safety of fixed low-dose dalteparin in preventing venous thromboembolism among obese or elderly hospitalized patients. Arch Intern Med. 2005;165:341-345.

9. Kearon C, Khan SR, Agnelli G, Goldhaber S, Raskob GE, Comerota AJ. Antithrombotic therapy for venous thromboembolism disease: American College of Chest Physicians evidence-based clinical practice guidelines (8th Edition). Chest. 2008;133:454S-545S.

10. Boneu B, de Moerloose P. How and when to monitor a patient treated with low molecular weight heparin. Sem Thromb Hemost. 2001;27(5):519-522.

11. Mahé I, Gouin-Thibault I, Drouet L, Simoneau G, Di Castillo H, Siguret V, et al. Elderly medical patients treated with prophylactic dosages of enoxaparin. Drugs Aging. 2007;24(1):63-71.
Clinical Interventions in Aging

\section{Publish your work in this journal}

Clinical Interventions in Aging is an international, peer-reviewed journal focusing on evidence-based reports on the value or lack thereof of treatments intended to prevent or delay the onset of maladaptive correlates of aging in human beings. This journal is indexed on PubMed Central, MedLine, the American Chemical Society's 'Chemical

\section{Dovepress}

Abstracts Service' (CAS), Scopus and the Elsevier Bibliographic databases. The manuscript management system is completely online and includes a very quick and fair peer-review system, which is all easy to use. Visit http://www.dovepress.com/testimonials.php to read real quotes from published authors. 